\title{
To share or not to share: clonal integration in a submerged macrophyte in response to light stress
}

\author{
Susanne R. Wolfer $\cdot$ Dietmar Straile
}

\begin{abstract}
The ability of clonal plant species to share resources has been studied in many experiments. The submerged macrophyte Potamogeton perfoliatus produces interconnected ramets within short time intervals and hence may or may not share resources with ramets growing in less favourable microhabitats. From a genet point of view, sharing with ramets growing under less favourable conditions might not be an optimal strategy when photosynthates could be used to establish other ramets growing under more favourable conditions. To analyse the plasticity in clonal integration of $P$. perfoliatus, we set up a factorial aquaria experiment with unshaded or shaded recipient ramets (offspring), which were connected to or separated from donor ramets (parents). Increased biomass production of offspring in parent-offspring systems compared with severed offspring in both light and shade showed that ramets share resources through clonal integration. The relative translocation to the first- and second-offspring generation was influenced by habitat quality: If first-offspring ramets grew in a shaded microhabitat, second-offspring ramets clearly profited. This may be at least partially because of the fact that resources are shifted from first-offspring to
\end{abstract}

Handling editor: Sidinei Magela Thomaz

S. R. Wolfer · D. Straile ( $\triangle)$

Limnological Institute, University of Konstanz,

78457 Konstanz, Germany

e-mail: Dietmar.Straile@uni-konstanz.de second-offspring ramets, indicating controlled senescence of the first-offspring. This complex sharing behaviour might be relevant when plants produce ramets within a dense patch of macrophytes, where support of a shaded ramet might not pay off.

Keywords Clonal architecture $\cdot$ Habitat heterogeneity - Biomass allocation Potamogeton . Plant senescence

\section{Introduction}

Clonal plants are characterised by the reiteration of potentially independent modules, called ramets, which consist of shoots, rhizomes or stolons, and roots. Clonal integration involves resource sharing through rhizomes or stolons and plays an important role in the regulation of shoot growth. The transport of water, nutrients, and photosynthates has been shown to increase the capacity of plants to tolerate resource heterogeneity, to colonise different microhabitats, and to recover from herbivory (Ong \& Marshall, 1979; Schmid et al., 1988; Alpert, 1999). The degree of resource sharing of a clonal plant species is under both genetical and environmental control (Alpert, 1999; van Kleunen et al., 2000). The primary motor behind clonal integration might be either the resource export from parents acting as a source (push model) or the demand of offspring acting as a sink (pull model) (Pitelka \& Ashmun, 1985; Marshall \& Price, 1997). 
Among aquatic plants, clonal integration is known from emergent macrophytes (Hester et al., 1994; Amsberry et al., 2000), floating stoloniferous species (Methy et al., 1990; Li \& Wang, 2011), submerged macrophytes (Xiao et al., 2007), and marine seagrasses (Tomasko \& Dawes, 1989; Marbà et al., 2002).

Although clonal integration might enable ramets to develop at less suitable microhabitats (e.g., Tomasko \& Dawes, 1989; Methy et al., 1990), modelling analyses suggest that support of such ramets might not always be beneficial for the genet, especially when there are other ramets in more suitable microhabitats (Gardner \& Mangel, 1999). However, until recently most studies analysing clonal integration almost exclusively focussed on resource sharing, but did not examine conditions when resource sharing with a specific ramet might not be profitable (but see Hellström et al., 2006).

Here, we analyse whether resource sharing occurs with a ramet growing at a less suitable microhabitat of the submerged rhizomatous freshwater species Potamogeton perfoliatus $\mathrm{L}$. This species can form large patches that can facilitate other macrophyte species when threatened by herbivory or eutrophication (Le Bagousse-Pinguet et al., 2012a, b). In situ surveys in Lake Constance revealed that each $P$. perfoliatus plant sprouts from a turion in spring and produces horizontal rhizomes of up to $1.5-\mathrm{m}$ length, bearing up to 15 ramets during a short vegetation period (Wolfer \& Straile, 2004a, b). Because of the rapid establishment of subsequent ramets, several newly established ramets can occur, and it is not clear whether a ramet in a less suitable habitat will be supported.

We tested for the effects of shading of one offspring (i.e., growing in a less suitable microhabitat) on the growth of two offspring generations in a $2 \times 2$ factorial aquarium experiment. The first offspring was either left connected to or severed from the parental ramet. Hence, we analysed the relative performance of two ramets in a 3-ramet system (connected) and in a 2-ramet system (severed). At the start of the experiment, the second of the focal ramets was not yet established. Consequently, in the 2-ramet system where no support from the parent is possible, the success of the clonal fragment depends on the photosynthesis of the shaded ramet. In contrast, in the 3-ramet system, the shaded ramet is not crucial for the success of the clonal fragment as the parent ramet can share resources with the unshaded offspring. Hence, we tested the following two hypotheses:

(1) Total biomass of offspring ramets in the 3-ramet (parent-offspring) system is enhanced as compared with biomass of offspring ramets in the 2-ramet system (severed offspring system), i.e., there is clonal integration between parent and offspring.

(2) The shaded first-offspring ramet benefits less from clonal integration than the unshaded second-offspring ramet in the 3-ramet system.

\section{Materials and methods}

Origin and pre-cultivation of plant material

Potamogeton perfoliatus shoots were collected at the Lower Basin of Lake Constance, a large meso-oligotrophic lake in central Europe $\left(9^{\circ} 18^{\prime} \mathrm{E}, 47^{\circ} 39^{\prime} \mathrm{N}\right)$. All shoots originated from the same patch with a diameter of approximately $15 \mathrm{~m}$ and had an intermediate developmental age. Becuase they were cut off above the sediment, they had no rhizomes and no roots when planted. The shoots were planted across three aquaria (length: $80 \mathrm{~cm}$, width: $40 \mathrm{~cm}$, height: $50 \mathrm{~cm}$ ), filled with $10 \mathrm{~cm}$ of natural sediment from Lake Constance, and supplied with 1251 of filtered lake water. The water was exchanged twice a week; light was provided by pairs of white and plant-grow tubes (light intensity: $40 \mu \mathrm{E} \mathrm{m}^{-2} \mathrm{~s}^{-1}$ ) at $14 \mathrm{~h}$ a day. The experiment was started after the ramets were well established and had formed short second-offspring shoots.

\section{Experimental design}

The experiment started when all planted shoots (parent plants, P) had established one offspring ramet $\left(\mathrm{O}_{1}\right)$, i.e., the first focal ramet. About $50 \%$ of the focal ramets were left connected to their parent, $50 \%$ were severed from their parent. In addition, habitat heterogeneity with regard to light conditions was introduced in $50 \%$ of the connected and severed observation units by shading $\mathrm{O}_{1}$ with cylinder-shaped nets (Agroflor, height: $40 \mathrm{~cm}$, diameter: $6 \mathrm{~cm}$, shading effect: 63\%) (Fig. 1). Eight replicates of each treatment were distributed randomly across the three 


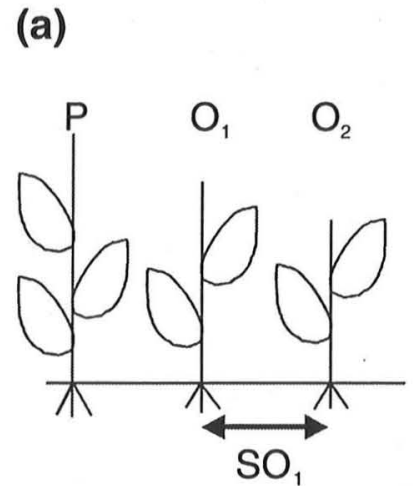

Fig. 1 Sketch of $\mathbf{a}$ an experimental unit $\mathbf{b}$ of the experimental design. Abbreviations as used in the text: $P$ parent ramet; $O_{1}$ first-offspring ramet, and $O_{2}$ second-offspring ramet as the two focal ramets; $\mathrm{SO}_{1}$ spacer length between focal ramets. Rhizomes

aquaria. At the beginning of the experiment, neither shoot lengths of $\mathrm{P}$ ramets $(31 \pm 8 \mathrm{~cm})$ nor shoot lengths of $\mathrm{O}_{1}$ ramets $(12 \pm 5 \mathrm{~cm})$ differed between treatments. The experiment was ended after 3 weeks when plants had produced the second focal ramet $\left(\mathrm{O}_{2}\right)$. The plants were carefully removed from the sediment with their rhizomes and roots and thoroughly washed. After the measurement of shoot lengths and lengths of the rhizomes between $\mathrm{O}_{1}$ and $\mathrm{O}_{2}$-called spacer length $\left(\mathrm{SO}_{1}\right)$ below-shoot, rhizome, and root fractions were dried at $105^{\circ} \mathrm{C}$, cooled down, and weighed on an analytic scale.

Resource sharing was inferred from increased shoot length and biomass in connected compared with severed focal ramets (Tomasko \& Dawes, 1989; Amsberry et al., 2000), but results are only presented for biomass, because analyses based on shoot measurements yielded consistent results.

\section{Statistical analysis}

Before analyses, shoot biomasses were log- and proportional data arcsine square root transformed to ensure normality and homogeneity for variances. Effects of shading and severing on total offspring biomass and the biomass ratio of $\mathrm{O}_{1}$ versus $\mathrm{O}_{2}$ were analysed with a linear mixed model with shading and severing and their interaction as fixed factors. Treatment effects on biomasses of $\mathrm{O}_{1}$ and $\mathrm{O}_{2}$ were separately analysed with a mixed model with four treatment levels and subsequent Tukey's post hoc

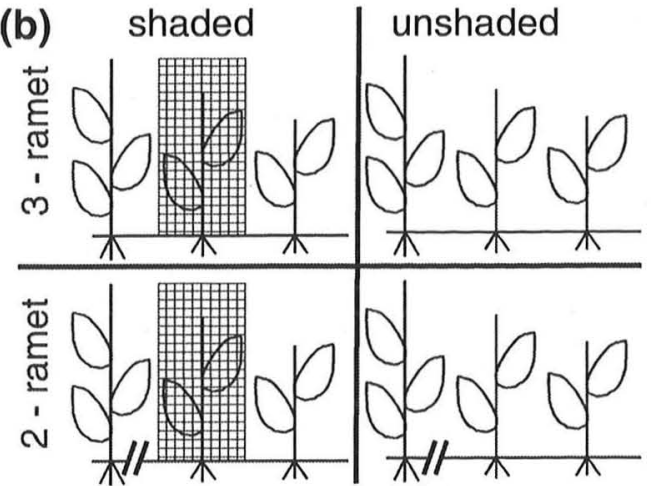

between $\mathrm{P}$ and $\mathrm{O}_{1}$ were either left connected or severed midway between the shoots. $\mathrm{O}_{1}$ ramets, but not $\mathrm{O}_{2}$ ramets, were either kept unshaded or shaded

comparison (Hothorn et al., 2008). In addition, we performed a linear mixed model with shading, severing, and ramet order as fixed factors to explicitly test for interactions of ramet order with severing and shading.

Root, shoot, and rhizome allocation of $\mathrm{O}_{1}$ were calculated by dividing the respective biomasses by total biomass of $\mathrm{O}_{1}$ (shoot biomass + root biomass + rhizome biomass). Effects of severing and shading on biomass allocation and on spacer length $\left(\mathrm{SO}_{1}\right)$ were analyzed with mixed models with shading and severing and their interaction as fixed factors. To investigate whether observed variability in $\mathrm{SO}_{1}$ was primarily because of allometry, i.e., differences in shoot biomass of $\mathrm{O}_{1}$, we additionally ran models using $\mathrm{O}_{1}$ shoot biomass as a covariate in models.

All statistical models were set up as mixed models in the nlme package of $\mathrm{R}$ (Pinheiro et al., 2011). All models considered besides fixed factors (see above) the random factor "aquarium" to account for slight differences in growth conditions between aquaria. Likelihood ratio tests were used to assess the significance of the random factor and indicated significance levels between 0.01 and 0.6 in the different models. However, to present conservative significance levels for the fixed effects, the random factor was included in all models. We do not report individual likelihood ratio test with the exception of Table 1 . Likelihood ratio tests were also used in the model with shoot biomass as covariate to analyse which fixed factors significantly contribute to the model. 
Table 1 Effects of shading, severing, and ramet order on shoot biomass

\begin{tabular}{lrrr}
\hline & DF & $F$ value & $P$ value \\
\hline Severing & 1,48 & 59.5 & 0.0001 \\
Shading & 1,48 & 13.6 & 0.0006 \\
Ramet order & 1,48 & 35.5 & 0.0001 \\
Severing $\times$ shading & 1,48 & 0.9 & 0.3449 \\
Severing $\times$ ramet order & 1,48 & 15.9 & 0.0002 \\
Shading $\times$ ramet order & 1,48 & 0.8 & 0.3748 \\
Severing $\times$ shading $\times$ ramet order & 1,48 & 6.4 & 0.0147 \\
\hline
\end{tabular}

Linear mixed model with shoot biomass (log transformed) as dependent variable and severing, shading, ramet order (first or second offspring) and their interactions as fixed factors. To account for possible aquaria effects on shoot biomass, "aquarium" was included as a random factor in the model. A likelihood ratio test $(L R=2.999)$ suggests the inclusion of this random factor with $P=0.083$

\section{Results}

Clonal integration

After 3 weeks of growth, severing had reduced total shoot biomass of focal ramets $\left(\mathrm{O}_{1}+\mathrm{O}_{2}\right)$ strongly $(63 \%$ reduction, mixed model; $F_{1,23}=30.8, P<0.0001$, Fig. 2), whereas shading of the first offspring $\left(\mathrm{O}_{1}\right)$ had a smaller effect ( $30 \%$ reduction, $F_{1,23}=5.8, P<0.05$ ). Shading did not influence the response of focal ramet shoot biomass to being severed (severing $\times$ shading interaction: $F_{1,23}=0.03, P=0.86$ ). Biomass of parent ramets was affected neither by severing nor by shading of $\mathrm{O}_{1} \quad\left(F_{1,20}=2.3, \quad P=0.15\right.$, and $F_{1,20}=0.09$,

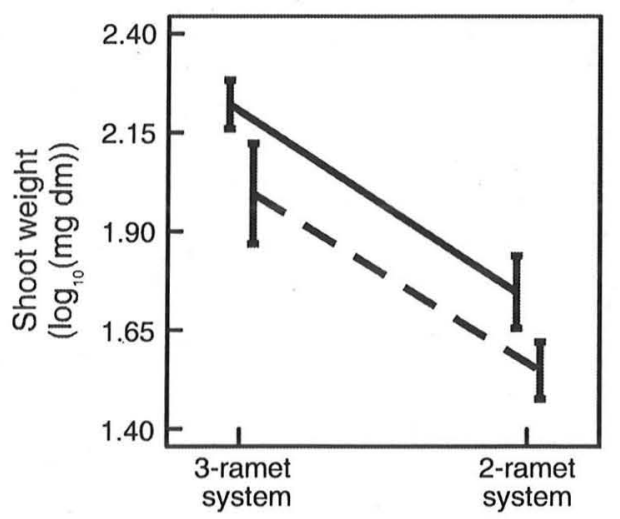

Fig. 2 Total shoot biomass of both focal ramets (mean \pm SE) of $P$. perfoliatus in the 2-ramet versus 3-ramet system. Solid lines indicate "light," hatched lines indicate "shade" treatments
$P=0.77)$ nor by their interaction $\left(F_{1,20}=0.02\right.$, $P=0.88)$.

Focal ramets were differently affected by severing and by shading (Fig. 3). Biomass of $\mathrm{O}_{1}$ was highest in the 3-ramet light treatment as compared with all other treatments (Fig. 3). When shaded, there was no significant biomass difference between the 2- and 3-ramet systems, meaning that $\mathrm{O}_{1}$ performance was not significantly increased by the presence of a parent. In contrast, $\mathrm{O}_{2}$ did profit from the 3-ramet system under both light and shade conditions (of $\mathrm{O}_{1}$ ). Furthermore, its biomass increase because of clonal integration was higher when $\mathrm{O}_{1}$ was shaded than when $\mathrm{O}_{1}$ was unshaded. Shading of $\mathrm{O}_{1}$ did not influence the biomass of $\mathrm{O}_{2}$ in the 3-ramet system. As a consequence, biomass of $\mathrm{O}_{2}$ was similar to the biomass of $\mathrm{O}_{1}$ in the 3-ramet shade treatment, but was less than $\mathrm{O}_{1}$ in all other treatments (Fig. 3).

As a consequence of different responses of $\mathrm{O}_{1}$ and $\mathrm{O}_{2}$ to severing and shading, the growth of $\mathrm{O}_{2}$ relatively to $\mathrm{O}_{1}\left(\mathrm{O}_{2} / \mathrm{O}_{1}\right)$ was significantly influenced by the interaction between severing and shading $\left(F_{1,23}=9.6\right.$,

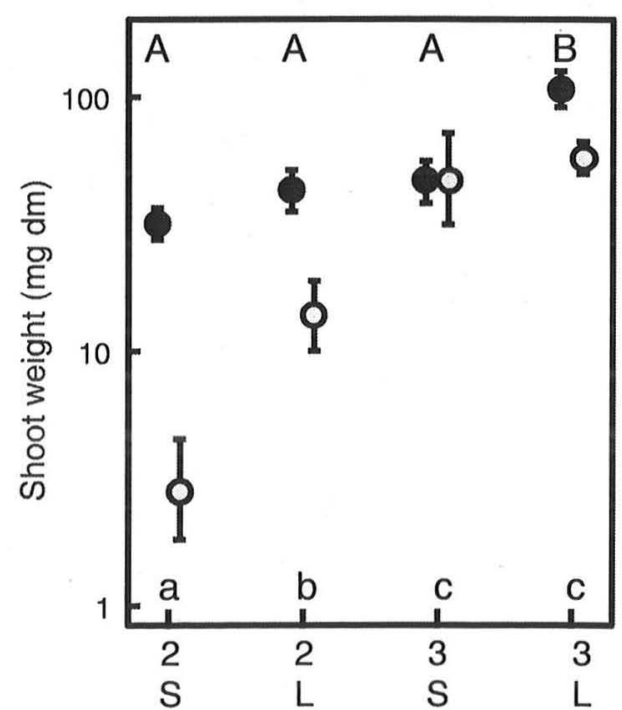

Fig. 3 Shoot biomass of the two focal ramets $\mathrm{O}_{1}$ (filled circles) and $\mathrm{O}_{2}$ (open circles) in the different treatments. Numbers 2 and 3 refer to the 2-, 3-ramet systems, respectively, $S$ shade, $L$ (light) refers to the two light conditions. There are significant treatment differences for $\mathrm{O}_{1}$ biomass (linear mixed model: $F_{3,23}=9.99$, $P<0.0002)$ and for $\mathrm{O}_{2}$ biomass $\left(F_{3,23}=18.0, P<0.0001\right)$. Capital letters at the top of the graph indicate treatment differences in $\mathrm{O}_{2}$ biomass, lower case letters at the bottom of the graph show treatment differences in $\mathrm{O}_{1}$ biomass. Different letters indicate significant differences between treatments (Tukey's post hoc test, $P<0.05$ ) 


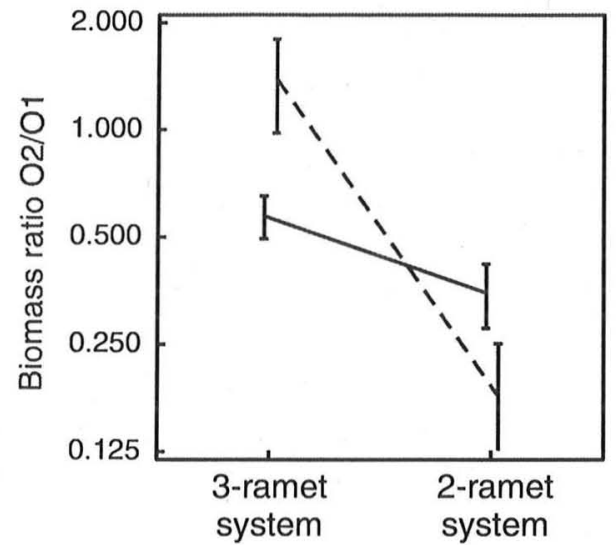

Fig. 4 Biomass ratio of second offspring and first offspring $\left(\mathrm{O}_{2} / \mathrm{O}_{1}\right)$ (mean $\left.\pm \mathrm{SE}\right)$ of $P$. perfoliatus grown in aquaria. Solid lines indicate "light," hatched lines indicate "shade" treatments

$P=0.005$, Fig. 4): Shading of $\mathrm{O}_{1}$ increased the $\mathrm{O}_{2} / \mathrm{O}_{1}$ biomass ratio when $\mathrm{O}_{1}$ was connected to a parent ramet, but decreased it when the connection was severed. This difference in response of the two focal ramets to shading in the 2- versus 3-ramet system is also supported by a significant three-way interaction: severing $\times$ shading $\times$ ramet order in a mixed model distinguishing the two focal ramets with the factor "ramet order" (Table 1).

Biomass allocation and spacer length

Root allocation of $\mathrm{O}_{1}$ was affected by the interaction between the shading and severing (Table 2): Shading increased root allocation of connected $\mathrm{O}_{1}$ but reduced it in severed $\mathrm{O}_{1}$ (Fig. 5a). No significant treatment effects (Table 2) were observed for shoot allocation (Fig. 5b) and rhizome allocation (Fig. 5c).

Spacer length $\left(\mathrm{SO}_{1}\right)$ was close to significantly related to the interaction between severing and shading interaction $\left(F_{1,25}=3.69, P=0.07\right)$, significantly to severing $\left(F_{1,25}=10.9, P<0.003\right)$, but not to shading $\left(F_{1,25}=0.4, P=0.55\right)$. With shoot biomass as a covariate, $\mathrm{SO}_{1}$ was significantly related to the interaction of shoot biomass and severing $\left(F_{1,25}=19.1\right.$, $P=0.0002)$, shoot biomass $\left(F_{1,25}=11.6, P=0.0022\right)$, and severing $\left(F_{1,5}=8.2, P=0.0084\right)$. While $\mathrm{SO}_{1}$ was negatively related to shoot biomass in 3-ramet systems, $\mathrm{SO}_{1}$ was positively related to shoot biomass in 2-ramet systems (Fig. 6). This suggests that the 3-ramet system $\mathrm{O}_{1}$ responded to growth conditions by increasing spacer length, whereas in the 2-ramet system, $\mathrm{O}_{1}$ responded to growth conditions by decreasing spacer length. Inclusion of shading and its interactions with shoot biomass or severing did not significantly improve the model with severing and shoot biomass as fixed factors (Likelihood ratio tests, all $P>0.05$ ). This suggests that possible effects of shading on $\mathrm{SO}_{1}$ may be because of effects of shading on $\mathrm{O}_{1}$ shoot biomass.

\section{Discussion}

\section{Clonal integration}

The substantially higher biomass of offspring in the 3-ramet systems as compared with the 2-ramet systems shows that parent ramets of $P$. perfoliatus were capable of sharing resources acropetally through clonal integration. However, clonal integration was not uniform, but rather sensitive to the growth conditions of the first focal ramet: $O_{1}$ ramets substantially benefited from integration only when in the light but were not supported when shaded. In contrast, many previous studies have found physiological integration especially where recipient ramets experienced stress through resource limitation in heterogeneous environments (Alpert \& Stuefer, 1997; Hutchings \& Wijesinghe, 1997; Alpert, 1999). For example, connected shaded

Table 2 Effects of shading and severing on root, rhizome, and shoot allocation

\begin{tabular}{llll}
\hline & Severing & Shading & Severing $\times$ shading \\
\hline Root allocation & $F_{1,26}=4.62, P=0.04$ & $F_{1,26}=3.48, P=0.07$ & $F_{1,26}=7.6, P=0.01$ \\
Rhizome allocation & $F_{1,26}=0.12, P=0.73$ & $F_{1,26}=0.92, P=0.34$ & $F_{1,26}=0.02, P=0.88$ \\
Shoot allocation & $F_{1,26}=0.19, P=0.67$ & $F_{1,26}=0.21, P=0.65$ & $F_{1,26}=2.47, P=0.13$ \\
\hline
\end{tabular}

Linear mixed model results with allocations (arcsine square root transformed) as dependent variable and severing, shading, their interaction as fixed factors. To account for possible aquaria effects on shoot growth, "aquarium" was included as a random factor in the models 

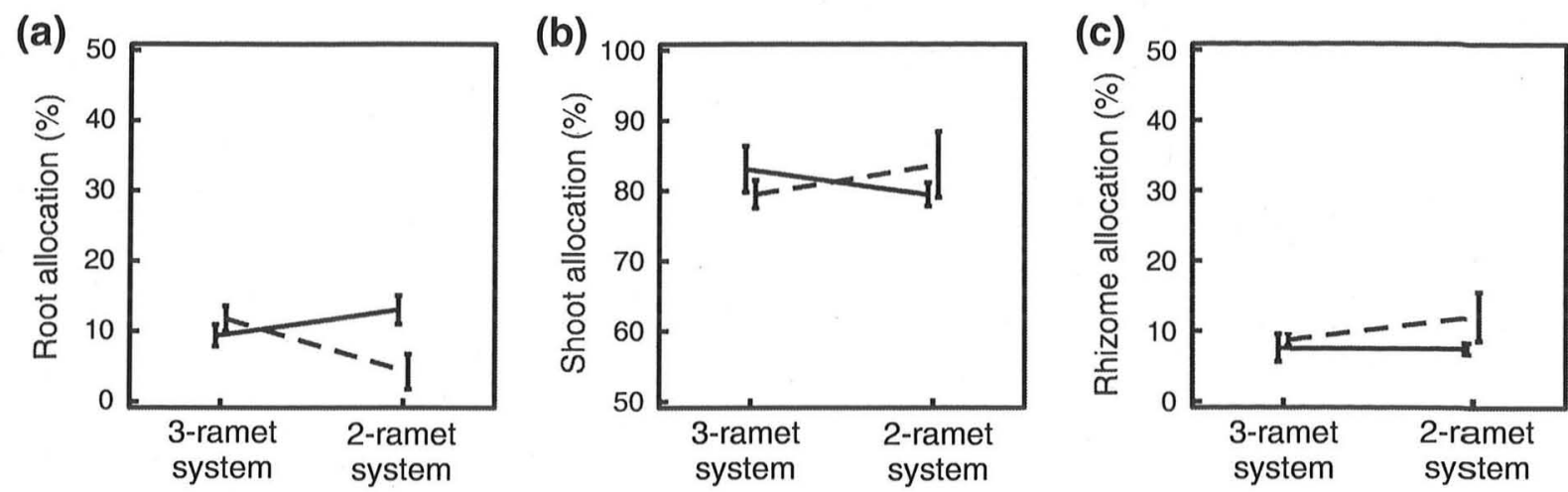

Fig. 5 a Root, b shoot, and $\mathbf{c}$ rhizome allocation $\pm \mathrm{SE}$ of 2- and 3-ramet system of $P$. perfoliatus first offspring $\left(\mathrm{O}_{1}\right)$. Solid lines indicate "light," hatched lines indicate "shade" treatments

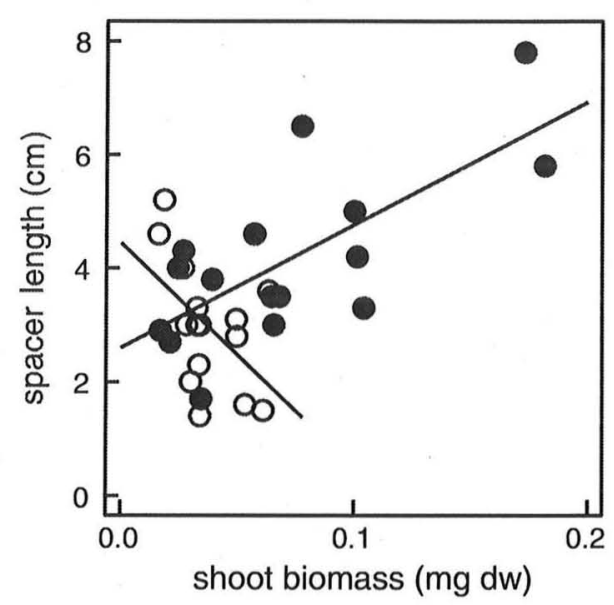

Fig. 6 Spacer length between focal ramets $\left(\mathrm{SO}_{1}\right)$ in relation to first offspring $\left(\mathrm{O}_{1}\right)$ shoot biomass. Filled symbols indicate 3-ramet system treatments, open symbols indicate 2-ramet system treatments

shoots of the seagrass Thalassia testudinum achieved growth rates equal to non-shaded controls (Tomasko \& Dawes, 1989). Likewise, severely shaded ramets of Lolium perenne continued to grow and produced new leaves as a result of physiological integration (Ong \& Marshall, 1979), and shaded shoots of Eichhornia crassipes suffered less when connected to parent shoots growing in the light (Methy et al., 1990). However, in our study, the proximal offspring $\left(\mathrm{O}_{1}\right)$ benefited from the 3-ramet system, i.e., from the connection to its parental ramet only under full light, but was not supported when shaded. In the latter situation, the shaded ramet $\mathrm{O}_{1}$ was passed by and resources were directed to the distal offspring $\mathrm{O}_{2}$. Indeed, $\mathrm{O}_{2}$ ramets of $P$. perfoliatus benefited from resource sharing relatively more strongly when $\mathrm{O}_{1}$ ramets were shaded. This shows that clonal integration in $P$. perfoliatus can also occur between non-adjacent shoots (see also Terrados et al., 1997) and that resources are shared with distal offspring depending on the microhabitat, i.e., growth conditions, of the proximate offspring. Likewise, resource sharing has often been observed with ramets suffering from herbivory (Marshall \& Sagar, 1965; Schmid et al., 1988). However, lack of support for damaged ramets of a perennial herb has been demonstrated and attributed to competition between sibling ramets (Hellström et al., 2006).

Competition within branches of a plant has also been demonstrated in pine trees (Honkanen \& Haukioja, 1994) and pea plants (Novoplansky et al., 1989), and has been termed the branch-competition hypothesis (Sachs \& Novoplansky, 1997). This hypothesis predicts that a plant module that is inferior because of, e.g., herbivory damage or microhabitat unsuitability should be left out of support when more viable sinks are available. Our results are in line with this prediction. However, shaded $\mathrm{O}_{1}$ in the 3-ramet system showed even strong signs of chlorosis that was not the result of shading per se, as shaded $\mathrm{O}_{1}$ in the 2-ramet system appeared vigorous and retained green leaves. This observation suggests that the branch-competition hypothesis is unlikely to give a complete explanation of our results: At the end of the experiment, shoot biomass of $\mathrm{O}_{1}$ and $\mathrm{O}_{2}$ was similar (Fig. 3). Assuming a faster growth rate of unshaded $\mathrm{O}_{2}$ relative to shaded $\mathrm{O}_{1}$ suggests that during most of the experimental time, biomass of $\mathrm{O}_{1}$ was larger than biomass of $\mathrm{O}_{2}$. It is, 
hence, difficult to believe that despite these biomass differences, competitive superiority of $\mathrm{O}_{2}$ was large enough to result into chlorosis of $\mathrm{O}_{1}$. Rather, the large differences in performance of $\mathrm{O}_{1}$ suggest controlled senescence of shaded $\mathrm{O}_{1}$ in the 3-ramet treatment possibly associated with remobilization of resources (Ong \& Marshall, 1979; Stapel \& Hemminga, 1997) towards $\mathrm{O}_{2}$. Hence, integration seems to have qualitatively altered the response of shaded $\mathrm{O}_{1}$ by inducing a novel response, i.e., chlorosis (de Kroon et al., 2005). Interestingly, controlled senescence of $P$. perfoliatus has also been suggested as a response to intense herbivory (Miler \& Straile, 2010): High herbivory pressure of a lepidopteran larvae resulted in retranslocation of nutrients from shoots to overwintering organs and consequently to senescence of shoots. This suggests that controlled senescence is a behaviour highly important for the response of the species to biotic and abiotic factors, and should be considered in future studies aiming to model the temporal and spatial dynamics of this species (e.g., Wolfer et al., 2006).

Biomass allocation and spacer length

Shading increased root allocation of connected offspring but reduced root allocation in severed offspring. Our analyses suggest that the differences in biomass allocation are not because of allometric growth rules, which predict that smaller plants show a higher biomass allocation to belowground structures (Müller et al., 2000). In contrast to this prediction, $\mathrm{O}_{1}$ in 2-ramet shade systems had the lowest root allocation despite their small biomass. This might result from a shortage of carbohydrates and the need to invest in shoot biomass (Alcoverro et al., 1997). The lower root allocation in the severed shaded offspring compared with higher root allocation in connected shaded offspring is also in line with the foraging hypothesis proposing that single plants specialise in the most limiting resource (here light), and integrated plants specialise in the most abundant resource (here probably nutrients) (Stuefer et al., 1996). In a clonal ramet system with "division of labour" (Hutchings \& Wijesinghe, 1997), ramets may continue to take up nutrients by roots even when they are non-photosynthetic (Jonsdottir \& Callaghan, 1990), and in our experiment, shaded $\mathrm{O}_{1}$ may still contribute to plant growth by supplying nutrients to unshaded $\mathrm{O}_{2}$.
As in some terrestrial plants (Wijesinghe \& Handel, 1994; van Kleunen et al., 2000), severing significantly reduced spacer lengths of $P$. perfoliatus offspring. This might be attributed to the stronger effect of severing on offspring shoot biomass, and to the overall positive relationship between shoot biomass and spacer length. In situ, spacer length of $P$. perfoliatus strongly increases with distance from the primary ramet, possibly as a consequence of an increasing biomass and production of an interconnected clonal fragment with the number of produced ramets (Wolfer $\&$ Straile, 2004b). As a result of shading, $\mathrm{O}_{1}$ in the 3-ramet system responded to the infavourable growth conditions by decreasing spacer length. However, $\mathrm{O}_{1}$ in the 2-ramet system responded to shade conditions by increasing spacer length, even though shoot biomass was slightly decreased. This is in line with the predictions of the foraging hypothesis: Shaded shoots are expected to produce longer rhizomes to "escape" from the unfavourable habitat (Hartnett \& Bazzaz, 1983; Sutherland \& Stillman, 1988). Possibly, foraging is only expressed in the growth patterns when growth is strongly impaired by shading, and integration is not possible (but see de Kroon \& Hutchings, 1995 for a critical discussion of the plant foraging hypothesis).

To conclude, our experiment has shown that (1) $P$. perfoliatus parent ramets support their clonal offspring ramets through translocation of resources, i.e., there is clonal integration within a genet and (2) the relative translocation of resources to different offspring generations depends on the habitat quality of the individual ramets: Ramets in unfavourable microhabitats, e.g., under light stress, are not integrated when support of other ramets provides higher benefits for the genet. This behaviour might be highly relevant when plants produce new ramets within dense patches of macrophytes (Wolfer \& Straile, 2004a, b). In such a case, it might not benefit the plant to support a severely shaded ramet, but rather to invest in rhizome growth and new ramets at the outer perimeter of the patch, where microhabitats are more suitable.

Acknowledgments We thank the Special Collaborative Project (SFB) 454 "Bodenseelitoral" at the University of Konstanz and RIZA/Lelystad for financial support and J. F. Stuefer. H. Coops, and M. Scheffer for valuable comments on an earlier version of the manuscript. Comments by two anonymous reviewers and the editor improved the manuscript considerably. 


\section{References}

Alcoverro, T., J. Romero, C. M. Duarte \& N. I. Lopez, 1997. Spatial and temporal variations in nutrient limitation of seagrass Posidonia oceanica growth in the NW Mediterranean. Marine Ecology-Progress Series 146: 155-161.

Alpert, P., 1999. Clonal integration in Fragaria chiloensis differs between populations: ramets from grassland are shelfish. Oecologia 120: 69-76.

Alpert, P. \& J. F. Stuefer, 1997. Division of labour in clonal plants. In van Groenendael, J. \& H. deKroon (eds), The Ecology and Evolution of Clonal Plants. Backhuys Publishers, Leiden: 137-154.

Amsberry, L., M. A. Baker, P. J. Ewanchuk \& M. D. Bertness, 2000. Clonal integration and the expansion of Phragmites australis. Ecological Applications 10: 1110-1118.

de Kroon, H. \& M. J. Hutchings, 1995. Morphological plasticity in clonal plants: the foraging concept reconsidered. Journal of Ecology 83: 143-152.

de Kroon, H., H. Huber, J. F. Stuefer \& J. M. van Groenendael, 2005. A modular concept of phenotypic plasticity in plants. New Phytologist 166: 73-82.

Gardner, S. N. \& M. Mangel, 1999. Modeling investments in seeds, clonal offspring, and translocation in a clonal plant. Ecology 80: 1202-1220.

Hartnett, D. C. \& F. A. Bazzaz, 1983. Physiological integration among intraclonal ramets in Solidago canadensis. Ecology 64: 779-788.

Hellström, K., M. M. Kytoviita, J. Tuomi \& P. Rautio, 2006. Plasticity of clonal integration in the perennial herb Linaria vulgaris after damage. Functional Ecology 20: 413-420.

Hester, M. W., K. L. McKee, D. M. Burdick, M. S. Koch, K. M. Flynn, S. Patterson \& I. A. Mendelssohn, 1994. Clonal integration in Spartina patens across a nitrogen and salinity gradient. Canadian Journal of Botany 72: 767-770.

Honkanen, T. \& E. Haukioja, 1994. Why does a branch suffer more after branch-wide than after tree-wide defoliation. Oikos 71: 441-450.

Hothorn, T., F. Bretz \& P. Westfall, 2008. Simultaneous inference in General Parametric Models. Biometrical Journal 50: 346-363.

Hutchings, M. J. \& D. K. Wijesinghe, 1997. Patchy habitat, division of labour and growth dividends in clonal plants. Trends in Ecology \& Evolution 12: 390-394.

Jonsdottir, I. S. \& T. V. Callaghan, 1990. Intraclonal translocation of ammonium and nitrate nitrogen in Carex bigelowii Torr Ex Schwein using N-15 and nitrate reductase assays. New Phytologist 114: 419-428.

Le Bagousse-Pinguet, Y., E. M. Gross and D. Straile, 2012a. Release from competition and protection determine the outcome of plant interactions along a grazing gradient. Oikos 121: 95-101.

Le Bagousse-Pinguet, Y., P. Liancourt, N. Gross and D. Straile, $2012 \mathrm{~b}$. Indirect facilitation promotes macrophyte dominance in freshwater ecosystems threatened by eutrophication. Journal of Ecology. doi:10.1111/j.1365-2745.2011. 01931.x.

Li, W. G. \& J. B. Wang, 2011. Influence of light and nitrate assimilation on the growth strategy in clonal weed Eichhornia crassipes. Aquatic Ecology 45: 1-9.
Marbà, N., M. A. Hemminga, M. A. Mateo, C. M. Duarte, Y. E. M. Mass, J. Terrados \& E. Gacia, 2002. Carbon and nitrogen translocation between seagrass ramets. Marine Ecology Progress Series 226: 287-300.

Marshall, C. \& E. A. C. Price, 1997. Sectoriality and its implications for physiological integration. In deKroon, H. \& J. van Groenendael (eds), The Ecology and Evolution of Clonal Plants. Backhuys Publishers, Leiden: 79-107.

Marshall, C. \& G. R. Sagar, 1965. Influence of defoliation on distribution of assimilates in Lolium multiflorum Lam. Annals of Botany 29: 365-370.

Methy, M., P. Alpert \& J. Roy, 1990. Effects of light quality and quantity on growth of the clonal plant Eichhornia crassipes. Oecologia 84: 265-271.

Miler, O. \& D. Straile, 2010. How to cope with a superior enemy? Plant defence strategies in response to annual herbivore outbreaks. Journal of Ecology 98: 900-907.

Müller, I., B. Schmid \& J. Weiner, 2000. The effect of nutrient availability on biomass allocation patterns in 27 species of herbaceaous plants. Perspectives in Plant Ecology, Evolution and Systematics 3: 115-127.

Novoplansky, A., D. Cohen \& T. Sachs, 1989. Ecological implications of correlative inhibition between plant shoots. Physiologia Plantarum 77: 136-140.

Ong, C. K. \& C. Marshall, 1979. Growth and survival of severely-shaded tillers in Lolium perenne L. Annals of Botany 43: 147-155.

Pinheiro, J., D. Bates, S. DebRoy, D. Sarkar and the R Development Core Team, 2011. nlme: linear and nonlinear mixed effects models. R package version 3.1-100.

Pitelka, L. \& J. Ashmun, 1985. Physiology and integration of ramets in clonal plants. In Jackson, J. B. C., L. W. Buss \& R. E. Cook (eds), Population Biology and Evolution of Clonal Organisms. Yale University Press, New Haven, Connecticut: $399-436$.

Sachs, T. \& A. Novoplansky, 1997. What does aclonal organization suggest concerning clonal plants? In van Groenendael, J. \& H. deKroon (eds), The Ecology and Evolution of Clonal Plants. Backhuys Publishers, Leiden: 55-78.

Schmid, B., G. M. Puttick, K. H. Burgess \& F. A. Bazzaz, 1988. Clonal integration and effects of simulated herbivory in old-field perennials. Oecologia 75: 465-471.

Stapel, J. \& M. A. Hemminga, 1997. Nutrient resorption from seagrass leaves. Marine Biology 128: 197-206.

Stuefer, J. F., H. de Kroon \& H. J. During, 1996. Exploitation of environmental heterogeneity by spatial divison of labour in a clonal plant. Functional Ecology 10: 328-334.

Sutherland, W. J. \& R. A. Stillman, 1988. The foraging tactics of plants. Oikos 52: 239-244.

Terrados, J., C. M. Duarte \& W. J. Kenworthy, 1997. Is the apical growth of Cymodocea nodosa dependent on clonal integration? Marine Ecology Progress Series 158: 103-110.

Tomasko, D. A. \& C. J. Dawes, 1989. Evidence for physiological integration between shaded and unshaded short shoots of Thalassia testudinum. Marine Ecology Progress Series 54: 299-305.

van Kleunen, M., M. Fischer \& B. Schmid, 2000. Clonal integration in Ranunculus reptans: by-product or adaptation? Journal of Evolutionary Biology 13: 237-248. 
Wijesinghe, D. K. \& S. N. Handel, 1994. Advantages of clonal growth in heterogenous habitats: an experiment with Potentilla simplex. Journal of Ecology 82: 495-502.

Wolfer, S. R. \& D. Straile, 2004a. Density control of clonal growth of Potamogeton perfoliatus. Limnologica 34: 98-104.

Wolfer, S. R. \& D. Straile, 2004b. Spatio-temporal dynamics and plasticity of clonal architecture in Potamogeton perfoliatus. Aquatic Botany 78: 307-318.
Wolfer, S. R., E. H. van Nes \& D. Straile, 2006. Modelling the clonal growth of the rhizomatous macrophyte Potamogeton perfoliatus. Ecological Modelling 192: 67-82.

Xiao, K. Y., D. Yu, X. W. Xu \& W. Xiong, 2007. Benefits of clonal integration between interconnected ramets of $\mathrm{Val}$ lisneria spiralis in heterogeneous light environments. Aquatic Botany 86: 76-82. 